\title{
A Study on Students' Instrumental Motivation for English Learning in Chinese Universities
}

\author{
Dongmei Wang \\ School of Foreign Studies, Yangtze University, Jingzhou 434023, China \\ 244676463@qq.com
}

Keywords: instrumental motivation; English learning; enhancing methodology

\begin{abstract}
Learner's motivation is a focus and discussed by many researchers from various perspectives in language learning and teaching. College students' English learning motivation is one of these research subjects. It has great impact on the frequency of using learning strategies, the acceptance of second language input, the interaction with the native speakers, the setting of goals and the learner's determination of learning a foreign language. Based on Gardner's motivation dichotomy, this thesis adopts quantitative approach to study students' instrumental motivation for English learning in Chinese universities. This study is done for the following purposes: firstly, to identify students' instrumental motivation, and then to accordingly provide some helpful suggestions on how to enhance their English learning.
\end{abstract}

\section{Introduction}

\subsection{Definition of Motivation.}

As an essential and complicated variable in second language learning, the characteristics of motivation attract many scholars home and abroad to carry on their researches. However, there is still no universally accepted definition, not to say a complete depiction of the features.

Among all these various definitions, Gardner's concept of motivation is most well-known and frequently adopted. He defines motivation to learn a second language (Gardner, 1985) as "the extent to which the individual works or strives to learn the language because of a desire to do so and the satisfaction experienced in this activity". He (Tremblay \& Gardner, 1995) suggests that this concept indicates three different parts: (a) a desire to learn the target language, (b) satisfaction of learning the language successfully, (c) effort to realize a goal in learning.

Two major classifications of motivation are widely discussed: instrumental /integrative motivation and extrinsic / intrinsic motivation.

\subsection{Instrumental/Integrative Motivation}

According to Gardner (1985), learners with strong instrumental motivation are eager to acquire a new language as an approach to realizing practical or functional goals. The learning is due to an ulterior motive which is not related to its native speakers, in other words, for some instrumental reasons, such as meeting the demands of passing different tests, going to college, reading technical materials for specific information, hunting for a job, requesting better pay, or achieving higher social status. They are also likely to learn as those learners with integrative motivation do, however they do so just because of necessity, not satisfaction.

In contrast to instrumental motivation, learners with strong integrative motivation worship the target culture that they are learning, and thus want to learn as much as possible about its culture, history, society and are curious about everything related. Therefore, for these learners, the process of second language acquisition is a pretty pleasant way of finding new things. To identify with the target culture, learners may look for opportunities to practice the language, listen to its music, read its literature. In a word, the integrative motivation indicates the extent to which the learners identify with the target culture or not.

On the basis of these four motivation types which consist of intrinsic, extrinsic, integrative, and instrumental motivation, Özgür and Griffiths (2013) found out second language learners are strongly motivated by instrumental purposes, such as using English to get a better job or study abroad. 


\section{Research Design and Methodology}

This paper is designed to analyze the college students' instrumental motivation for second language learning, and offer beneficial suggestions to improve college teaching and learning accordingly.

It is strongly desired that it can enhance the understanding of students' motivation currently. What's more, I hope to hold a thorough idea on making full use of the valuable findings in and to work out practical keys to the difficult questions.

The situation in which the study was conducted is Yangtze University (hereinafter referred to as YU). Here we surveyed the instrumental motivation for English learning in this university, because on the one hand, the research is conveniently conducted since the author is an assistant professor of English in YU, and on the other hand (which is also the most important one), to some extent, the university may be representative of many universities in China.

The choice of students can stand for diversity of the study. 134 students from various majors in Yangtze University are chosen to finish the questionnaire within the given time. All of them are non English majors. Like most of there peers in other Chinese universities English classes, they are supposed to have at least six English classes a week. Students in Yangtze University spend a lot of time having two or more English courses. All of them were very helpful and took the survey seriously.

A questionnaire about students' instrumental motivation is designed and adopted in the process. The primary purpose, to identify students' instrumental motivation for English Learning, requires the investigation of a relatively large number of students' perceptions of English. For this special aim, the questionnaire is the most appropriate method - primarily for logistical reasons, due to the large number of students, but also because adopting a questionnaire allows shy students to respond without embarrassment. The date was analyzed by EXCEL.

In the questionnaire, students are presented with six questions and required to give their answers (Likert scales) their varying degrees of: Agreement: strongly disagree - 1, disagree - 2, neutral - 3, disagree - 4, strongly agree - 5. The questionnaire was conducted on September 28, 2015 in Yangtze University.

The questionnaire mentioned above was finished with the help of the English teacher. The author distributed the questionnaires to all participants and made specific explanation about each question. All the subjects were free to ask any questions about the items on the questionnaire. Students were asked to finish all the relevant questions within 12 minutes, and then they were collected. When the students were working on the questionnaire, the teacher helped with one or two statements when they didn't understand. Generally speaking, there were no big problems of understanding.

\section{Instrumental motivation}

Table 1 Instrumental Motivation of Chinese College Students

\begin{tabular}{|c|c|c|c|c|c|c|}
\hline Question & mean & 5 & 4 & 3 & 2 & 1 \\
\hline Q1 & 4.20 & $36.79 \%$ & $49.06 \%$ & $11.22 \%$ & $2.93 \%$ & $0.00 \%$ \\
\hline Q2 & 2.82 & $2.83 \%$ & $18.87 \%$ & $42.45 \%$ & $26.42 \%$ & $9.43 \%$ \\
\hline Q3 & 4.16 & $41.41 \%$ & $34.55 \%$ & $11.43 \%$ & $6.67 \%$ & $4.93 \%$ \\
\hline Q4 & 3.70 & $21.70 \%$ & $43.40 \%$ & $18.87 \%$ & $15.09 \%$ & $0.94 \%$ \\
\hline Q5 & 2.91 & $3.87 \%$ & $17.82 \%$ & $46.17 \%$ & $27.42 \%$ & $4.72 \%$ \\
\hline Q6 & 3.28 & $8.59 \%$ & $33.86 \%$ & $42.45 \%$ & $5.46 \%$ & $9.63 \%$ \\
\hline
\end{tabular}

It is shown that $85.85 \%$ of students strongly agree or agree that learning English enable them to get more prestigious jobs in the future. No one strongly disagree with it. Over $85 \%$ of students agree or strongly agree that to get a high score in CET is very important for their future .About 41.4\% Chinese students strongly agree that to get a high score in CET is very important for their future. These two questions are closely related since it is common for enterprises in China to require CET-4 or even CET-6 certificates. Many colleges have the minimum requirement of passing the 
nation-wide CET-4 to get a bachelor's degree. CET imposes great influences on college English learning. Their English learning is totally "certificate-oriented". It is suggested that Chinese students feel great pressure for learning English to pass the exam because CET certificates are closely related to their future jobs. That can explain why there are even boards which remind them days towards CET at campus.

Students agree that learning English was essential to operate a computer, followed by expressing their own country more to the world.

The lowest mean responses were to study abroad and to work overseas. The percentage of "strongly agree" only accounted for $3.87 \%$. The comparatively low score for this last suggests that for most students, studying abroad or working abroad is beyond their expectations in their near future. It is clearly illustrated that at present, Chinese college students need to pass the English examination to get the academic score, and then they could get their diploma successfully. Therefore, a comparatively larger proportion of college students learn English in order to get CET certificate. This result corresponds with that of Shi (2000) and Gao (2003), who have proved the major English-learning motivation of Chinese learners is "certificate motivation", especially CET certificate for college students. This phenomenon could be explained as follows: CET has a great impact in China. They learn English just because they have to. Therefore, students without any CET certificate work hard for a CET-4 certificate while students who have got CET-4 certificate study for a CET-6 certificate. People always use CET certificate as a standard to evaluate a student's English ability. Therefore, in order to prove themselves, college students have to work for a CET certificate. Since CET imposes such a great influence on college students' English learning, it is of great importance to study whether there is any difference in students' English learning motivation after CET reform.

\section{Suggestions \& Conclusion}

\subsection{Varying Teaching Patterns}

The focus of CET reform is to cultivate learners' English application ability, which requires that students should be the leading role in the classroom activities; therefore, Chinese English teachers should change their teaching patterns, trying to let college students find the great pleasure of learning English, which is helpful to foster their intrinsic interest.

There are a number of ways to promote language learners' interest, such as making the tasks varied and challenging. Making change in teaching patterns quite necessary for holding students' motivation. The excitement of going to universities may provide students with great learning motivation at the very beginning. However, dull teaching methodology will makes students fell bored very soon. Therefore, holding various activities that they can engage in can help students keep the motivation for a longer period. It is really the teachers' responsibility to change the style, sequence, content and teaching methodology of English lectures.

\subsection{Making English Learning Individualized}

Students in modern society emphasize their individuality very much. Everyone wants to be different from others. Language teachers should pay more attention to this tendency. Language teaching is always carried out in mufti-media classroom today, which is helpful for teachers to activate all senses of the students. Teachers can stimulate students from every aspect as sound, light and color. Therefore, pictures, music or flash all could be used to present a colorful class to the students. Different demand of the learners could be satisfied at some level, so the class could be more attractive for them. Since their interests are stimulated, they may become more active and involve more time and energy in the following language learning.

\subsection{Encouraging Students to Interact with English Speakers}

One practical way is to chat with native speakers on Internet. For instance, students may engage in programs on Internet with native English speakers for communicative purposes and cultural exchanges al well. Development of science and internet technology has made emailing and video chatting whenever they want possible for most of the students. Students should make full use of it. 


\subsection{Remembering the Dynamic Feature}

Learning a foreign language is a long-term activity that may last for quite a few years to be successfully achieved, but language-learning motivation does not remain constant during the course. An initial interest in language learning cannot guarantee the motivational strength during the whole learning process; what's more, the external learning environment may also change (such as CET reform). Therefore, college teachers of English are always supposed to keep students' level of learning motivation in mind and provide enough guidance if necessary.

To sum up, there are a number of ways to enhance students' instrumental motivation in English learning. Strategies including varying teaching patterns, making English learning individualize are all supposed to intrigue students' learning motivation. It is advisable that all these strategies should be adopted dependently in class. At the same time, teachers should also adopt them according to different conditions. College teachers should bear students' English learning motivation in mind and guide them to stop it from declining.

\section{Appendix - A Questionnaire on Students’ Instrumental Motivation}

\begin{tabular}{|c|l|lllll|}
\hline 1 & $\begin{array}{l}\text { Learning English enable me to get a more prestigious job in the } \\
\text { future. }\end{array}$ & 5 & 4 & 3 & 2 & 1 \\
\hline 2 & I learn English because I want to study abroad. & 5 & 4 & 3 & 2 & 1 \\
\hline 3 & To get a high score in CET is very important for my future. & 5 & 4 & 3 & 2 & 1 \\
\hline 4 & Learning English is essential to operate a computer & 5 & 4 & 3 & 2 & 1 \\
\hline 5 & Learning English is essential because I want to work overseas. & 5 & 4 & 3 & 2 & 1 \\
\hline 6 & $\begin{array}{l}\text { Learning English enable me to make foreign people understand } \\
\text { China more. }\end{array}$ & 5 & 4 & 3 & 2 & 1 \\
\hline
\end{tabular}

\section{Reference}

[1] Cohen, A. D. Strategies in Learning and Using a Second Language, Foreign Language Teaching and Research Press.2000

[2] Jeremy Harmer. How to Teach English, Addison Wesley Longman 1998

[3] Keith Johnson. An Introduction to Foreign Language Learning and Teaching, Pearson Education Limited 2001

[4] Özgür B, Griffiths C. Second Language Motivation [J]. Proscenia-Social and Behavior Sciences, 2013

[5]Richards, J. Approaches and Methods in Language Teaching, Foreign Language Teaching and Research Press.2000

[6]Ur, P. A Course in Language Teaching: Practice and Theory, Foreign Language Teaching and Research Press.2000 